\title{
Acquired hemophilia A as a cause of acute upper gastrointestinal hemorrhage
}

\author{
Stephen McCain, Sadaf Gull, Jawad Ahmad, Declan Carey
}

Belfast City Hospital, Belfast, UK

\section{Correspondence to} S McCain, Belfast City Hospital, 51 Lisburn Road, Belfast BT9 7AB, UK; smccain02@qub.ac.uk

\begin{abstract}
SUMMARY
A 71-year-old man presented to the emergency department with his first episode of hematemesis. He was anemic and coagulopathic on admission, and became hemodynamically unstable requiring surgical intervention to control the bleeding. Prior to surgery, he required $100 \%$ plasma exchange with human plasma derived prothrombin complex concentrate (Octaplex) as the exchange fluid. At induction of anesthesia, he received tranexamic acid, prothrombin complex concentrate, and platelets. At the time of knife to skin, he was given coagulation factor VIla intravenously as a bolus. This treatment was on the recommendation of the hematology team who suspected a diagnosis of acquired hemophilia on the basis of his history and coagulation screen. His bleeding was controlled and a diagnosis of acquired hemophilia A was confirmed in the postoperative period. This was managed with immunosuppressive therapy, and at the 2 year follow-up he remains well and is off all treatment.
\end{abstract}

\section{BACKGROUND}

Upper gastrointestinal hemorrhage accounts for up to 70000 acute hospital admissions in the UK each year. Common causes include gastritis, Mallory Weiss tears, peptic ulcers, and gastroesophageal varices. More unusual etiologies include clotting disorders such as acquired hemophilia, congenital hemophilia, and Von Willebrands disease. ${ }^{1}$

Acquired hemophilia A (AHA) occurs when a patient develops autoantibodies to the clotting factor VIII. It affects approximately 1.48 per million people in the UK. Other forms of acquired hemophilia have been reported, including antibodies against factors II, V, VII, XI, and XIII, although type $\mathrm{A}$ is the most common form. ${ }^{1}$ Clinical suspicion is followed-up with laboratory investigations to confirm the diagnosis. Typically the prothrombin time (PT) is normal while there is a prolonged activated partial thromboplastin time (APTT). There will be reduced levels of clotting factor VIII and evidence of inhibitors to factor VIII. ${ }^{1} 2$

The case below describes an elderly patient who presented with a life threatening upper gastrointestinal hemorrhage caused by AHA.

\section{CASE PRESENTATION}

A 71-year-old man presented to the emergency department with acute onset hematemesis and hemoptysis. Past medical history included hypertension, hypercholesterolemia, and iron deficiency anemia. His anemia was diagnosed 3 weeks prior to his acute presentation after attending his general practitioner with hematuria.

He was hemodynamically stable on arrival in the emergency department. Examination was unremarkable with the exception of coarse inspiratory crackles at his left base. He had no family history of any bleeding disorders.

\section{INVESTIGATIONS}

Bloods results on admission revealed a hemoglobin level of $8.2 \mathrm{~g} / \mathrm{dL}$, mean corpuscular volume of $82 \mathrm{fL}$, white cell count of $8000 / \mathrm{mm}^{3}$, and platelets of $256000 / \mathrm{mm}^{3}$. His coagulation screen was deranged PT $17.5 \mathrm{~s}$, APTT $44.3 \mathrm{~s}$, and fibrinogen of $5.34 \mathrm{mg} / \mathrm{dL}$. His renal function, liver function, and electrolytes were normal.

A CT scan of the chest and abdomen on admission showed a dilated esophagus filled with debris. An urgent esophagogastroduodenoscopy was organized due to ongoing hematemesis, and revealed fresh blood in the esophagus. As the stomach was full of blood, the mucosa could not be visualized, and a bleeding point was not identified.

\section{DIFFERENTIAL DIAGNOSIS}

The differential diagnosis included all common causes of upper gastrointestinal hemorrhage, as mentioned above, but given a newly discovered coagulopathy, acquired hemophilia was also suspected.

\section{TREATMENT}

Due to ongoing hemorrhage the patient was transferred to the intensive care unit for stabilization prior to any further attempts at definitive intervention. He became progressively more coagulopathic over the next $24 \mathrm{~h}$ (PT $18.3 \mathrm{~s}$ and APTT $61.1 \mathrm{~s}$ ). Acquired hemophilia was suspected at this stage, and prior to laparotomy to control the bleeding the patient proceeded to have $100 \%$ plasma exchange with human plasma derived prothrombin complex concentrate (Octaplex) as the exchange fluid. At induction of anesthesia, he received $2 \mathrm{~g}$ of tranexamic acid, $1500 \mathrm{IU}$ of prothrombin complex concentrate repeated every $12 \mathrm{~h}$ for $48 \mathrm{~h}$, and 2 units of platelets. At the time of knife to skin, he was given $20 \mathrm{mg}$ of recombinant coagulation factor VIIa intravenously as a bolus.

During surgery a large blood clot was evacuated from his stomach with no obvious bleeding point identified but rather a general ooze was seen coming from the stomach. The esophagus was full of organized clot to a height of $30 \mathrm{~cm}$ and was manually removed via the stomach. Retrograde 
visualization with an endoscope revealed no specific bleeding point.

Postoperatively he remained unstable and coagulopathic requiring fresh frozen plasma, cryoprecipitate, and packed red cells. His remaining hematological investigations became available, showing that his factor VIII clotting assay was $0.02 \%(0.6-$ 1.3), and he had factor VIII inhibitor present at a level of 17.49 $\mathrm{BU} / \mathrm{ml}$. A diagnosis of AHA was confirmed.

Initially he was started on synthetic vasopressin (DDAVP) $0.3 \mu \mathrm{g} / \mathrm{kg}$ every $12 \mathrm{~h}$, human prothrombin complex (Octaplex) $1500 \mathrm{IU}$ every $12 \mathrm{~h}$, and recombinant human coagulation factor VII (Novoseven) $90 \mu \mathrm{g} / \mathrm{kg}$ every $3 \mathrm{~h}$. With this regimen the patient began to stabilize.

Once transferred out of the intensive care unit he was started on rituximab, cyclophosphamide, and vincristine therapy. Unfortunately he developed abdominal dehiscence postoperatively and had to return to theatre requiring further blood products as cover.

\section{OUTCOME AND FOLLOW-UP}

His admission was prolonged due to a chest infection and the need for rehabilitation. He remains well at the 2 year follow-up and is off all immunosuppressant therapy. He has a normal APTT, and factor VIII levels are satisfactory.

\section{DISCUSSION}

Acquired hemophilia is a life threatening autoimmune condition in which there is spontaneous development of antibodies against plasma coagulation factors. Antibodies against factor VIII are most common, and this type is known as AHA. ${ }^{1}$ Mortality rates have been estimated as 7.9-22\%, with most hemorrhagic deaths occurring within the initial weeks after presentation. ${ }^{1}{ }_{2}$ Acquired hemophilia is a separate entity from hereditary hemophilia, which is an $\mathrm{X}$ linked recessive condition present from birth and mainly affects men. ${ }^{1}$

The incidence has been estimated at 1.48 per million in the UK, with two age distribution peaks at 20-30 years and 6080 years. $^{3}$ Factor VIII inhibitors affect both sexes equally, although women predominate in the younger age group because of the association with pregnancy, while men make up the majority of patients over the age of 60 years. ${ }^{45}$

Acquired hemophilia should be suspected in any patient with no personal or family history of bleeding who presents with sudden onset hemorrhage with no precipitant or excessive bleeding after mild trauma. Eighty per cent of patients present with hemorrhage into the skin causing widespread bruising; the muscles with potential compartment syndrome; or mucous membranes causing epistaxis, gastrointestinal, and urological bleeds. Surgical patients with no previous history may have excessive bleeding during or following a procedure. ${ }^{15}$ One other paper reports blood loss of almost $2500 \mathrm{~mL}$ during cesarean section, with readmission 12 days later with massive vaginal bleeding. Hysterectomy failed to control the bleeding and three laparotomies were performed for hemostasis. In total, the patient required 32 units of packed red cells, 42 units of fresh frozen plasma, and 10 units of platelets. ${ }^{6}$

A diagnosis is confirmed by laboratory investigations. In AHA there is a classical picture of a normal PT with a prolonged APTT. $^{7}$ The APTT is not corrected when the patient's plasma is incubated with equal volumes of normal plasma in a mixing study. ${ }^{1}$ Other clinical situations in which the APTT is prolonged with a normal PT include treatment with low molecular weight heparin, presence of lupus anticoagulant, and either a deficiency or presence of inhibitors to clotting factors IX, X, and XII. ${ }^{8} 9$

Reduced levels of factor VIII and evidence of factor VIII inhibitors are required for a diagnosis to be made. Inhibitor level is measured in Bethesda units, and this level is used to help determine which treatment is appropriate. ${ }^{19}{ }^{10}$ If the Bethseda level is $<5$, low concentrates of human factor VIII and desmopressin are used. $^{1}$ Higher levels of inhibitor ( $>5$ Bethseda units) require further agents to control bleeding. These include porcine factor VIII concentrates, activated prothrombin complex concentrates, and recombinant activated factor VII. Although normally used separately, they have been reported to have been used successfully in combination when bleeding control is difficult. If surgery is required in these patients, the use of plasmapheresis is useful in the hours prior to surgery to reduce inhibitor levels. ${ }^{4} 11$

The longer term management of AHA requires elimination of factor VIII inhibitors. This most often requires immunosuppression, and the firstline agents used to do this include corticosteroids, cyclophosphamide, azathioprine, 6-mercaptopurine, and vincristine. Secondline therapy includes high dose immunoglobulins and ciclosporin. In patients with an underlying etiology, often treating the cause removes the inhibitors. ${ }^{1} 1011$

\section{Learning points}

- All bleeding patients should have a coagulation screen performed in addition to routine hematological and biochemical tests.

- Coagulopathy in the absence of an obvious cause should alert you to the possibility of an underlying congenital or acquired hemophilia.

- Multidisciplinary management, with early input from a gastrointestinal specialist and hematologist, of patients with gastrointestinal bleeding and coagulopathy is required to optimize patient outcome.

Contributors All authors have contributed appropriately to the research, drafting, and revision of the article.

Competing interests None.

Patient consent Obtained.

Provenance and peer review Not commissioned; externally peer reviewed.

\section{REFERENCES}

1 Franchini M, Gandini G, Di Paolantonio T, et al. Acquired hemophilia A: a concise review. Am J Hematol 2005;80:55-63.

2 Yee TT, Taher A, Pasi KJ, et al. A survey of patients with acquired hemophilia in a hemophilia centre over a 28-year period. Clin Lab Haematol 2000;22:275-8.

3 Collins PW, Hirsch S, Baglin TP, et al. Acquired hemophilia A in the United Kingdom: a 2-year national surveillance study by the United Kingdom Haemophilia Centre Doctors' Organisation. Blood 2007;109:1870-7.

4 Ma AD, Carrizosa D. Acquired factor VIII inhibitors: pathophysiology and treatment. Hematology Am Soc Hematol Educ Program 2006;1:432-7.

5 Bouvry P, Recloux P. Acquired hemophilia. Haematologica 1994;79:550-6.

6 Hashimoto T, Yanaihara N, Sugiura K, et al. Acquired hemophilia A with massive hemorrhage after cesarean section. Jikeikai Med J 2011;58:17-21.

7 Cohen AJ, Kessler CM. Acquired inhibitors. Bailleres Clin Haematol 1996;9:331-54.

8 Chng WJ, Sum C, Kuperan P. Causes of isolated prolonged activated partial thromboplastin time in an acute care general hospital. Singapore Med J 2005:46:450-6.

9 Boggio LN, Green D. Acquired hemophilia. Rev Clin Exp Hematol 2001;5:389-404.

10 Kadir RA, Koh MB, Lee CA, et al. Acquired haemophilia, an unusual cause of severe postpartum haemorrhage. BJOG 1997;104:854-6.

11 Collins PW. Treatment of acquired haemophilia A. J Thromb Haemost 2007:5:893-900. 
Copyright 2014 BMJ Publishing Group. All rights reserved. For permission to reuse any of this content visit http://group.bmj.com/group/rights-licensing/permissions.

BMJ Case Report Fellows may re-use this article for personal use and teaching without any further permission.

Become a Fellow of BMJ Case Reports today and you can:

- Submit as many cases as you like

- Enjoy fast sympathetic peer review and rapid publication of accepted articles

- Access all the published articles

- Re-use any of the published material for personal use and teaching without further permission

For information on Institutional Fellowships contact consortiasales@bmjgroup.com

Visit casereports.bmj.com for more articles like this and to become a Fellow 